\title{
Unconventional Implant Strategy for Patients With Limited Interocclusal Space in the Posterior Region: A Clinical Cohort Study With 1-year Follow-Up
}

\section{Xun Xia}

Fourth Affiliated Hospital of Nanchang University

Zhen-Yu Wei

Fuzhou Medical College of Nanchang University

Jiang-Qin Huang

Fourth Affiliated Hospital of Nanchang University

Chang-Qi Hu

Fourth Affiliated Hospital of Nanchang University

Shui-Gen Guo

Fourth Affiliated Hospital of Nanchang University

Li-Chun Yue

Fourth Affiliated Hospital of Nanchang University

Hong-Wu Wei ( $\nabla$ Nc.whw@163.com )

Fourth Affiliated Hospital of Nanchang University

Jin-Mei Gong

Fourth Affiliated Hospital of Nanchang University

\section{Research Article}

Keywords: Insertion depth, Limited interocclusal space, Locking taper implant

Posted Date: March 10th, 2021

DOI: https://doi.org/10.21203/rs.3.rs-225700/v1

License: (1) (1) This work is licensed under a Creative Commons Attribution 4.0 International License.

Read Full License 


\section{Abstract}

\section{Background}

This study aims to evaluate the clinical outcomes of a new implant restoration strategy for patients with limited interocclusal space in the posterior region.

\section{Materials and Methods}

A total of 37 patients (19 females and 18 males) were enrolled in this study and received 62 implants. A locking taper implant (Bicon) was used for the first stage procedure, which was placed $>2 \mathrm{~mm}$ under the bone. An extraoral cementation technique was used to cement the crown and abutment. The survival and success rate of the implant restorations were evaluated using the plaque index, modified bleeding index, probing depth, marginal bone loss, and the patient's subjective satisfaction.

\section{Results}

The soft tissues around the implant were healthy and did not show any indications of peri-implantitis. The success rate of the new implant restorations was $>96 \%$ at the 1 -year follow-up. The patients presented satisfactory outcomes at the 1-year follow-up. The marginal bone loss and soft tissue changes were not significantly different at different depths of placement $(p>0.05)$.

\section{Conclusions}

According to the results, the use of a locking taper implant and adoption of appropriate prosthetic strategies might be an effective procedure for the prosthetic rehabilitation of patients with limited interocclusal space and reduced occlusal vertical dimensions.

\section{Background}

Decreased occlusal vertical space and insufficient interocclusal space for a dental implant prosthesis is a common clinical problem [1]. According to Misch [2], the interocclusal space should be $\geq 8 \mathrm{~mm}$ in vertical distance. However, the interocclusal space in the posterior region might be reduced due to various factors, such as overeruption of the opposing teeth in the edentulous,[3] and wear of the occlusal surface of the natural dentition. To restore the interocclusal space, various approaches have been used, such as grinding or orthodontic intrusion of the opposing extruded teeth, removal of alveolar ridge osteotomy, the extraction method for occlusal reconstruction, personalized abutment, and integrated abutment crown. However, each method has certain limitations, for example, grinding of over-erupted vital teeth is efficient and might create 1-2 mm space; however, it might cause symptoms, such as dentine hypersensitivity or pulpitis.

The removal of the alveolar ridge should only be considered when there is sufficient bone height at the implant site. The posterior maxillary segmental osteotomy (PMSO) [5] might restore the occlusal curve of 
the missing teeth by moving the opposing tooth segment. The major disadvantages of osteotomy are technically difficulty, surgical trauma, and postoperative complications. The orthodontic intrusion of teeth is widely used combined with the mini-implant nail anchor method, which creates a 2-4 $\mathrm{mm}$ restoration space by anchoring the posterior teeth [6]. This technology restores the original restoration space and occlusal curve, but it is technical, has a longer treatment time, and has associated risks of root resorption and tooth torsion [7]. Personalized abutment could be considered for patients with limited interocclusal space. Bittner[8] used wide-necked implants and personalized larger mesiodistal diameter abutments to reinforce anchorage. However, the fabrication of personalized abutment is more expensive and there are occlusal forces at the implant restoration. Integrated abutment crowns could be used, where the abutment and the crown are directly fabricated in the laboratory or bonded chemically. The occlusal surface screw hole has been used for screw retention or self-locking taper retention (i.e., Bicon implants) [9]. Although the integrated abutment crown has certain advantages, such as restoring space, and no residual adhesive, there are certain problems when using the screw-retained implant-abutment interface. First, the screw hole destroys the integrity of the crown structure that might cause porcelain collapse [10]. Second, it is not easy to achieve passive emplacement and there is an increased incidence of mechanical complications. Finally, due to microleakage and micromovement of the implant-abutment interface [11], the implant-abutment interface might not be located deep under the bone.

Recently, Wang et al [12] proposed an unconventional protocol for the prosthetic management of patients with limited interocclusal space. The basic steps of the proposed method are: (1) primary surgery to place implants deeply; (2) second-stage surgery and removal of the bone tissues that affect the crown emplacement using a sulcus reamer; (3) designing the crown with a subgingival edge; therefore, the height of the abutment body is $\geq 5 \mathrm{~mm}$; and (4) extraoral cementation technique to fit the abutment and crown. This research claimed that the proposed strategy was simple, minimally invasive, convenient, and required no additional equipment or tools. In addition, the soft and hard tissue contour was preserved, and good sealing was achieved through the locking taper design, which could effectively reduce the probability of biological complications. However, all these findings are based on one case report [12] and require further clinical cohort studies to validate the results. Therefore, this study aims to evaluate the clinical outcomes of this new implant restoration strategy for patients with limited interocclusal space in the posterior region over 1 year.

\section{Materials And Methods}

Study design and patient selection

This study was approved by the ethical review board at Nanchang University, China. This study was conducted in the Department of Implantology, Fourth Affiliated Hospital of Nanchang University (Ref No:SFYYXLL-PJ-2021-KY008). The following inclusion criteria were applied to recruit patients for this study [n = 37 (18 males and 19 females)].

1. Good state of general health, and no chronic systemic diseases. 
2. Patients required dental implant treatment in the posterior maxilla.

3. Preoperative cone beam computed tomography (CBCT) demonstrated the distance from the antagonist teeth to the implant site bone plane was $<7 \mathrm{~mm}$, and the height from the antagonist teeth to the mandibular neural tube was $>13 \mathrm{~mm}$.

4. Any patient with a history of temporomandibular joint disease, severe bruxism, oral ulcers, or precancerous lesions was excluded.

In addition, intraoral examination and nonsurgical periodontal treatment were carried out to assure healthy oral condition. The aim of the study was explained to all patients and informed consent was obtained from every patient.

Implant placement

For each patient, preoperative CBCT was performed to ensure that the implant placement space was $\geq 6 \mathrm{~mm}$ and the distance from the implant neck to the antagonist teeth was $>7 \mathrm{~mm}$. The depth of implant placement was recorded. Then, $30 \mathrm{~min}$ before the surgical procedure, each patient was premedicated orally with an Ibuprofen sustained-release capsule $(100 \mathrm{mg})$ and dexamethasone acetate tablet $(2 \mathrm{mg})$. Chlorhexidine $(0.12 \%)$ and iodophor were used for oral and skin disinfection, respectively.

The surgical procedures were all performed under the supervision of an experienced oral surgeon and used local anesthesia (4\% articaine hydrochloride and 1:100,000 epinephrine; Pierrel, Milan, Italy). The implants were placed immediately or delayed.

Delayed implant placement: A full-thickness mucoperiosteal flap was raised at the alveolar ridge crest. The depth was determined by the preoperative $\mathrm{CBCT}$, and a cavity was drilled using the drilling sequence recommended by the manufacturer. The locking taper implants (Bicon LLC, Boston, MA, USA) were placed. The polyethylene healing plug was trimmed to the level of the ridge top, the harvested bone was placed, and the surgical site was sutured.

Immediate implant placement: According to the preoperative design, the implant hole was prepared following minimally invasive tooth extraction. The locking tapered implants were placed (Bicon LLC, Boston, MA, USA), and the healing plug was trimmed to the level of the alveolar ridge on the buccal side.

In particular, the depth of the implant should be equal to or greater than the planned depth. Patients were prescribed amoxicillin (1500mg tds for 5 days) and $0.12 \%$ chlorhexidine mouth rinsing three times a day for 7 days. Patients were recalled after 3 days to evaluate the wound healing. The second-stage surgery was performed after 3 months in the delayed implant placement group, and after 4 months for the immediate implant placement group. Following local infiltration, a crestal incision was made to remove the healing plug. The sulcus former was rotated on the guide pin to remove bone tissues that might affect the prosthesis. Titanium temporary abutment was installed to form the cuff.

\section{Prosthodontic treatment}


The implant level transfer impression was made 2-4 weeks following the abutment installation. The separated single crown and abutment prosthesis was designed as subgingival, semianatomical/nonanatomical cusp, where the height of the abutment body was $\geq 5 \mathrm{~mm}$. The fabricated prosthesis was tested in the mouth to ensure a good position of the abutment-implant and crown-abutment. The crown and abutment were combined using the extraoral cementation technique. The excess adhesive was removed. The patients were recalled biannually for a follow-up examination and nonsurgical periodontal treatment. The clinical and imaging evaluation was performed 1 year postoperatively. Representative images of various clinical procedures are shown in Fig. 1.

All CBCT images were taken at the intercuspal position and used Carestream CS 9300 Select (Carestream Health, Inc, France).

Follow-up and evaluation

Following 1 year of functional loading, evaluation of the prosthesis referred to the definition of implant success, survival, and failure published by Misch [13]. Various clinical indicators, such as modified plaque index (mPI), modified sulcus bleeding index (mSBI), and probing depth (PD) were reviewed and evaluated. All data were measured by the same dentist using a periodontal probe (15 UNC/CP-11.5B Screening Color-Coded Probe, Hu-Friedy, Chicago, IL, USA). In addition, the mechanical complications, such as if the implant or abutment fractured or cracked, the abutment loosened, or the crown cracked were recorded.

The radiographic evaluation was performed using Digimizer Image Analysis Software (V4.5.1, MedCalc Software bvba, Ostend, Belgium). Images were calibrated according to the image length and true length of the implant. The distance from the first thread of the implant to the crest of the alveolar ridge was measured to determine the marginal bone level. The mesial and distal bone heights at the prosthetic insertion were recorded at the time of functional loading as $\mathrm{ML}(0), \mathrm{DL}(0)$, and the 1-year follow-up as $M L(T), D L(T)$. Average bone resorption was recorded at the mesial marginal bone loss $(M B L)=M L(T)-$ $\mathrm{ML}(0)$, and the distal $\mathrm{MBL}=\mathrm{DL}(\mathrm{T})-\mathrm{DL}(0)$;

Average $\mathrm{MBL}=($ Mesial MBL + Distant MBL) 2

The imaging measurement was performed by an assistant blind to the study design. All images were measured once every 2 days, and the average value was taken three times. The satisfaction survey was conducted according to the evaluation method of Pjetursson [14]. The visual analog scale with 0 points (very dissatisfied) and 100 points (very satisfied) was used for statistical analysis.

Data analysis

The SPSS v24 was used to analyze the data. The Kolmogorov-Smirnov test was used to test the normal distribution of the data. Descriptive statistics (mean value, standard deviation, and range) are presented. The predictive variables included patient age, gender, implantation site, bone type, restoration type, smoker or not, whether to implant immediately, implant depth, implant diameter, and implant length. 
Outcome variables were implant failure and marginal bone resorption. The $\mathrm{X} 2$ test was used to analyze the relationship between independent variables and implant failure. Kruskal-Wallis test was used to determine the relationship between implant depth and $\mathrm{mPI}, \mathrm{mSBI}$, and PD. A generalized estimation equation was used to analyze the relationship between predictive variables and marginal bone resorption. A significance level of 0.05 was used for all statistical analysis.

\section{Results}

The demographic information of the study participants and the characteristics of implants and prosthesis are given in Table 1.

Table 1. Summary of basic information 


\begin{tabular}{|c|c|c|c|}
\hline Basic information & Classification & Number & Percent $₫ \% \bigotimes$ \\
\hline \multirow[t]{2}{*}{ Gender } & Female & 19 & 51 \\
\hline & Male & 18 & 49 \\
\hline \multirow[t]{2}{*}{ Age (years) } & $>55$ & 26 & 70 \\
\hline & $\geq 55$ & 11 & 30 \\
\hline \multirow[t]{2}{*}{ Installation site } & Maxilla & 11 & 30 \\
\hline & Mandible & 27 & 70 \\
\hline \multirow[t]{4}{*}{ Bone quality } & Type I & 8 & 13 \\
\hline & Type II & 39 & 63 \\
\hline & Type III & 14 & 22 \\
\hline & Type IV & 1 & 2 \\
\hline \multirow[t]{3}{*}{ Prosthesis } & All ceramic & 38 & 61 \\
\hline & Zirconia & 16 & 26 \\
\hline & Co-Cr alloy PFM & 8 & 13 \\
\hline \multirow[t]{2}{*}{ Smoker } & No & 42 & 68 \\
\hline & Yes & 20 & 32 \\
\hline \multirow[t]{2}{*}{ Immediate implant placement } & No & 53 & 85 \\
\hline & Yes & 9 & 15 \\
\hline \multirow[t]{4}{*}{ Implant depth } & $2 \mathrm{~mm}$ & 8 & 13 \\
\hline & $3 \mathrm{~mm}$ & 31 & 50 \\
\hline & $4 \mathrm{~mm}$ & 16 & 26 \\
\hline & $5 \mathrm{~mm}$ & 7 & 11 \\
\hline \multirow[t]{3}{*}{ Implant diameter } & $\mathrm{D}=4.5$ & 29 & 47 \\
\hline & $D=5$ & 27 & 43 \\
\hline & $D=6$ & 6 & 10 \\
\hline \multirow[t]{2}{*}{ Implant length (mm) } & 6 & 23 & 37 \\
\hline & 8 & 39 & 63 \\
\hline
\end{tabular}

This study included a total of 37 patients (19 female, 18 male) who received 62 implants (Table 1). A total of 35 patients (60 implants) met the success criteria with a success rate of $96.7 \%$ implants. One 
implant in a patient (male, 47 years old, tooth \#36) failed following 1 month of loading and another patient exhibited bone resorption around the implant ( $\leq 3$ threads) at 1-year follow-up. There were no mechanical complications during the follow-up period. All patients maintained good oral hygiene and periodontal health during the follow-up period. Only one patient reported signs of peri-implantitis. The clinical evaluation parameters of 62 implants at 1-year follow-up are presented in Table 2.

Table 2. Summary of clinical parameters

\begin{tabular}{|llll|}
\hline & Mean & Median & $\mathrm{SD}$ \\
$\mathrm{mPI}$ & 0.42 & 0.5 & 0.38 \\
$\mathrm{mSBI}$ & 0.46 & 0 & 0.65 \\
$\mathrm{PD} \Downarrow \mathrm{mm} \rrbracket$ & 2.4 & 2.42 & 0.51 \\
\hline
\end{tabular}

For the placement of at various depths under the bone, there was no statistical difference in the periodontal condition $(p>0.05)$ (Table 3$)$.

Table 3. Relationship between different implantation depth and $\mathrm{mPI}, \mathrm{mSBI}$, and PD (mean \pm SD)

\begin{tabular}{|llll|}
\hline & $\mathrm{mPI}$ & $\mathrm{mSBI}$ & $\mathrm{PD}(\mathrm{mm})$ \\
\hline $2 \mathrm{~mm}$ & $0.44 \pm 0.40$ & $0.38 \pm 0.52$ & $2.31 \pm 0.53$ \\
\hline $3 \mathrm{~mm}$ & $0.54 \pm 0.41$ & $0.68 \pm 0.65$ & $2.42 \pm 0.36$ \\
\hline $4 \mathrm{~mm}$ & $0.40 \pm 0.34$ & $0.56 \pm 0.73$ & $2.54 \pm 0.81$ \\
\hline $5 \mathrm{~mm}$ & $0.29 \pm 0.37$ & $0.17 \pm 0.41$ & $2.40 \pm 0.42$ \\
\hline Kruskal-Wallis test & $p=0.424$ & $p=0.253$ & $p=0.982$ \\
\hline
\end{tabular}

At 1-year follow-up, the mean MBL changes were $0.14 \pm 0.42 \mathrm{~mm}$ and the mesial and distal MBL were $0.18 \pm 0.52 \mathrm{~mm}$ and $0.10 \pm 0.42 \mathrm{~mm}$, respectively. There was no statistically significant difference in bone resorption at the mesial and distal edges $(T=-1.319, p=0.192)$.

The generalized estimation equation was used to evaluate the possible risk factors that affected the MBL of the implants (Table 4). Between the various indicators, the factors that affected MBL included gender $(p=0.03)$, age $(p=0.04)$, bone quality $(p=0.01)$, and the implant diameter $(p<0.01)$.

Table 4. Risk factor analysis for MBL that used a generalized estimating equations model 


\begin{tabular}{|c|c|c|c|}
\hline Variable & $\mathrm{MBL}[\mathrm{x} \pm \mathrm{sd}(\mathrm{mm})]$ & Wald X2 & $p$-value \\
\hline \multicolumn{4}{|l|}{ Gender } \\
\hline Female & $-0.20 \pm 0.10$ & \multirow[t]{2}{*}{4.747} & \multirow[t]{2}{*}{$0.04^{*}$} \\
\hline Male & $-0.04 \pm 0.07$ & & \\
\hline \multicolumn{4}{|l|}{ Age (years) } \\
\hline$<55$ & $0.26 \pm 0.78$ & \multirow[t]{2}{*}{4.109} & \multirow[t]{2}{*}{$0.04^{*}$} \\
\hline$\geq 55$ & $-0.19 \pm 0.10$ & & \\
\hline \multicolumn{4}{|l|}{ Installation site } \\
\hline Maxilla & $-0.02 \pm 0.09$ & 3.001 & 0.08 \\
\hline Mandible & $-0.20 \pm 0.11$ & & \\
\hline \multicolumn{4}{|l|}{ Bone quality } \\
\hline Type I & $0.33 \pm 0.22$ & & \\
\hline Type II & $0.00 \pm 0.08$ & 10.574 & $0.01 *$ \\
\hline Type III & $-0.13 \pm 0.15$ & & \\
\hline Type IV & $-0.42 \pm 0.15$ & & \\
\hline \multicolumn{4}{|l|}{ Prosthesis } \\
\hline All ceramic & $-0.06 \pm 0.08$ & & \\
\hline Zirconia & $-0.13 \pm 0.10$ & 0.447 & 0.80 \\
\hline Co-Cr alloy PFM & $-0.06 \pm 0.12$ & & \\
\hline \multicolumn{4}{|l|}{ Smoke } \\
\hline No & $-0.00 \pm 0.08$ & 2.301 & 0.15 \\
\hline Yes & $-0.16 \pm 0.11$ & & \\
\hline \multicolumn{4}{|c|}{ Immediate implant placement } \\
\hline No & $-0.07 \pm 0.07$ & 0.059 & 0.80 \\
\hline Yes & $-0.09 \pm 0.11$ & & \\
\hline \multicolumn{4}{|l|}{ Installation depth } \\
\hline $2 \mathrm{~mm}$ & $-0.14 \pm 0.12$ & & \\
\hline $3 \mathrm{~mm}$ & $-0.19 \pm 0.66$ & 7.210 & 0.06 \\
\hline $4 \mathrm{~mm}$ & $-0.19 \pm 0.11$ & & \\
\hline
\end{tabular}




\begin{tabular}{|llll|}
\hline $5 \mathrm{~mm}$ & $0.20 \pm 0.14$ & & \\
Implant diameter & & & \\
\hline$D=4.5$ & $-0.29 \pm 0.13$ & & \\
$D=5$ & $-0.16 \pm 0.08$ & 11.561 & $<0.00^{*}$ \\
$D=6$ & $0.21 \pm 0.11$ & & \\
Implant length (mm) & & & \\
6 & $-0.25 \pm 0.12$ & 3.775 & 0.05 \\
8 & $0.09 \pm 0.10$ & & \\
\hline
\end{tabular}

According to the satisfaction survey conducted at the 1-year follow-up, patients showed very high satisfaction rates for function and aesthetics (overall satisfaction $=96.86 \pm 3.44$ ) points. For $95 \%$ of implant sites, patients believed that the therapeutic effect of implant restoration met or exceeded expectations. Patients did not complain of temporomandibular joint discomfort.

\section{Discussion}

The study investigated the clinical outcomes of an unconventional implant strategy for patients with limited interocclusal space in the posterior region. A total of 62 locking taper implants were placed deep under the bone, restored using an abutment crowns prosthesis, and followed-up for 1 year. The success rate of the implants was evaluated using various indices (e.g., $\mathrm{mPI}, \mathrm{mSBl}$, and $\mathrm{PD}$ ) and patient's subjective satisfaction. At 1 year follow-up, the success rate was high ( $>96 \%)$ without any mechanical complications being observed. The MBL of the implant was $0.14 \pm 0.42 \mathrm{~mm}$ and there were no biological and mechanical complications due to increased placement depth.

Between the various indicators, MBL was significantly affected by gender $(p=0.03)$, age $(p=0.04)$, bone quality $(p=0.01)$, and implant diameter $(p<0.01)$. The differences in MBL for gender, age, and bone quality might be associated with osteoporosis and decreased hormone levels in elderly female patients. However, MBL remained within an ideal range. In this study, an increase in the implant diameter reduced the MBL. The implant diameter has an important role in stress dispersion, which is consistent with Baldassarri et al [16].

Reduction of interocclusal space or occlusal vertical dimension has been observed in dental patients that lost their teeth periodically and did not receive any oral rehabilitation[1]. A common method to restore the interocclusal space is the simultaneous removal of the alveolar crest at the implant site. Although this approach is convenient and does not increase the number of operations, it is associated with the loss of bone and soft tissues in the vertical direction and aesthetic outcomes. In addition, the soft tissues inconsistency with the neighboring teeth could encourage food impaction and might lead to periimplantitis[17]. 
The implant restoration strategy used in this study has advantages at each stage. The surgical procedure is consistent with traditional surgical procedures and techniques. The restoration of bone tissue was maximized by locking taper implants. There is evidence for single-tooth restoration with $6 \mathrm{~mm}$ implants in the posterior region [18]. Therefore, this strategy is convenient and could be considered in cases where the distance between the jaw and the important anatomical structure was $>13 \mathrm{~mm}$. In addition, deep placement of dental implant has several benefits, such as improved stress distribution to the bone around the implant [19] and enhanced sagittal width of the alveolar bone, which is beneficial to the placement of larger diameter implants. The diameter of the implant contributed more to stress distribution than the length of the implant [16]. In this study, the MBL significantly decreased $(p<0.01)$ by increasing the diameter of the implant.

This study used the accurate removal of bone tissues in the second-stage operation, which was different from simultaneous bone removal during primary surgery. The authors believe that any healthy tissue should not be removed, and the principles of prosthetic-driven deorganization should be followed due to the advantages, such as minimally invasive when obtaining the restoration space, and restoration of the bone tissues to support the soft tissues around the implant (which includes the mesial and distal, buccal and lingual). Therefore, there is no significant change in the vertical height of the soft tissues and the amount of attached gingiva is maintained. The width of the attached gingiva could be further increased following the placement of the temporary abutment. The restoration of the soft tissue contour along with the adjacent teeth avoids problems, such as food impaction.

In this study, the periodontal state around the implant restoration remained healthy and stable. Approximately $7 \%$ of the patients complained of occasional food impaction and the other patients reported that the prosthesis was easy to clean and had not caused any inflammation to the hard and soft tissues around the implant neck. External stimulation and bacterial invasion were minimized during primary healing and after crown repair. These types of prosthetic strategies provided better aesthetics outcomes, long-term stability, and were consistent with previous studies [20,21].

In this study, an extraoral cementation technique was used that is a simple and comfortable technique for cemented retention. The integrity of the occlusal surface was maintained, and the chances of mechanical failure were reduced. A major concern when using cemented retention is the residual adhesive that might contribute to the development of peri-implantitis [22]. To reduce the residual adhesive, various approaches have been suggested, such as the rubber dam method [23], copy abutment method [24], and lateral-screw-retained implant prosthesis [25]; however, these techniques do not apply to the subgingival prosthesis edge and the adhesive might not be removed. However, the extraoral cementation technique facilitated the complete removal of the residual adhesive; therefore, avoiding any irritation to the soft tissues. In addition, the crown contact relationship could be tested during the crown trial process after the implant-abutment was fully seated, which ensured that the implant-abutment interface achieved a complete bacterial seal. For the implant, this study selected the locking taper implant that involved minimally invasive repair methods and a bacterial seal at the implant-abutment interface [26], deep under the bone [9]. Its special plateau design allowed $6 \mathrm{~mm}$ or $5 \mathrm{~mm}$ to restore a single-tooth by using a 
solid abutment to reduce the incidence of mechanical complications [27]. Other implant systems could achieve a complete bacterial seal if there was insufficient restoration space using the method proposed in this study. When placing the implant deep under the bone, it is important to note that the implantabutment connection in screw retention could easily be obstructed by the bone tissues, which meant that it was difficult to achieve complete passive placement. In contrast, the abutment of the locking taper implant could be separated to facilitate clinical examination.

For soft tissue, this study achieved good results for the removal of the residual adhesive and complete bacterial closure at the implant-abutment interface. In this study, the patient's occlusal curve was not perfectly restored; however, the patients had no obvious temporomandibular joint symptoms during the follow-up period. Some studies [28-29] suggested that occlusal curve changes might lead to temporomandibular joint dysfunction combination with other factors. Several patients with abnormal occlusal curves did not develop temporomandibular joint disease. Patients often have adaptive changes in the joint due to the long-term lack of teeth. The restoration of occlusal curves based on the ideal curve does not necessarily lead to satisfactory masticatory function[30-31]. If there are a few missing teeth, even if the occlusal curve was not completely restored, the temporomandibular joint system was not adversely affected. Patients included in this study did not complain of temporomandibular joint discomfort during the follow-up period. However, it is not known whether the strategy could be used for repair when the curve has been severely disordered. The method chosen for implant prosthesis requires further research into different degrees of tooth elongation. For the strategies proposed in this study, further research, and clinical studies with larger sample size and longer follow-ups are required.

In summary, the advantages of this strategy included minimally invasiveness, time effectiveness, low technical sensitivity, and additional tools are not required. In addition, this study reported high patient satisfaction, a wide range of indications, the maximum extent of preservation, and the stability of the soft and hard tissues around the implant.

\section{Conclusion}

According to the results, the use of locking taper implants and adoption of appropriate prosthetic strategies might be an effective treatment for the prosthetic rehabilitation of patients with limited interocclusal space and reduced occlusal vertical dimension.

\section{Abbreviations}

PMSO: Posterior maxillary segmental osteotomy; CBCT: Cone beam computed tomography ; mPI: Modified plaque index; mSBI: Modified sulcus bleeding index ; PD: Probing depth; MBL: Marginal bone loss; ML: Mesial bone height; DL: Distal bone height.

\section{Declarations}




\section{Conflict of interest}

The authors declare no potential conflicts of interest.

\section{Acknowledgments}

The authors wish to thank Prof. Huang Deng in the Department of Pathology, NanChang University at The Fourth Affiliated Hospital of Nanchang University, for his academic help and time spent reviewing our study.

\section{Authors' contributions}

XX and ZY-W contributed to writing the paper; JQ-H, CQ-H, JM-G and SG-G contributed to data acquisition; LC-Y helped perform the analysis with constructive discussions; and HW-W contributed to the conception and design of the study. All authors read and approved the final manuscript.

\section{Funding}

This research did not receive any specific funding from public, commercial, or not-for-profit agencies.

\section{Availability of data and materials}

The datasets generated and/or analyzed during the current study are not publicly available due to inconsistent language expression, but are available from the corresponding author upon reasonable request.

\section{Ethics approval and consent to participate}

This study was conducted following the ethical guidelines defined by the World Medical Association as described in the Declaration of Helsinki released in 2013. This study was approved by the ethical review board at Nanchang University, China (Ref No:SFYYXLL-PJ-2021-KY008). Written informed consent was obtained from individual or guardian participants.

\section{Consent for publication}

Written informed consent was obtained from all patients for publication of this study and any accompanying images.

\section{Competing interests}

The authors declare no potential conflicts of interest.

\section{References}

1. Misch C E . Dental Implant Prosthetics (Second Edition)[M].Mosby. 2015. 
2. Craddock H L , Youngson C C, Manogue M, et al. Occlusal Changes Following Posterior Tooth Loss in Adults. Part 1: A Study of Clinical Parameters Associated with the Extent and Type of Supraeruption in Unopposed Posterior Teeth. Journal of Prosthodontics, 2007, 16(6):485-494. https://doi.org/10.1111/j.1532-849x.2007.00212.x

3. Muts EJ, van Pelt H, Edelhoff D, Krejci I, Cune M. Tooth wear: a systematic review of treatment options. J Prosthet Dent. 2014, 112(4):752-759.

4. https://doi.org/10.1016/j.prosdent.2014.01.018

5. Rachmiel A, Emodi $O$, Gutmacher Z , et al. Surgical treatment of unilateral severe overeruption and opposing alveolar atrophy. Quintessence international (Berlin, Germany : 1985), 2019, 50(6):462-468. https://doi.org/10.3290/j.qi.a42480

6. Kini S K, Muliya V S. Restoration of an endodontically treated premolar with limited interocclusal clearance. Indian J Dent Res, 2013, 24(4): 518-520. https://doi.org/10.4103/0970-9290.118383

7. Shin-Jae L, Sook-Yun J, Youn-Sic C, et al. Three-dimensional analysis of tooth movement after intrusion of a supraerupted molar using a mini-implant with partial-fixed orthodontic appliances. Angle Orthodontist, 2013, 83(2): 274-279. https://doi.org/10.2319/060912-480.1

8. Bittner $\mathrm{N}$, Lal K, Neurohr J . Fabrication of a custom abutment for a wide-diameter implant in a situation with limited interocclusal space. The Journal of prosthetic dentistry, 2009, 100(6):474-477. https://doi.org/10.1016/S0022-3913(08)60268-1

9. Urdaneta RA, Marincola M. The Integrated Abutment Crownt, a screwless and cementless restoration for single-tooth implants: a report on a new technique. J Prosthodont, 2007, 16(4): 311-8 https://doi.org/10.1111/j.1532-849x.2007.00194.x

10. Ferreiroa A, Peñarrocha-Diago $M$, Pradíes $G$,et al. Cemented and screw-retained implant-supported single-tooth restorations in the molar mandibular region: A retrospective comparison study after an observation period of 1 to 4 years. J Clin Exp Dent. $2015,7(1): 89-94$. https://doi.org/10.4317/jced.51708

11. Apaza-Bedoya K, Tarce M, Benfatti CAM, Henriques B, Mathew MT, Teughels W, Souza JCM. Synergistic interactions between corrosion and wear at titanium-based dental implant connections: A scoping review. J Periodontal Res. 2017, 52(6):946-954. https://doi.org/10.1111/jre.12469

12. Wang $Y$, Cen $W$, Huang $J Q$, et al. Unconventional implant strategy for patients with a limited interocclusal space in the posterior region: a case report. 2019:214. https://doi.org/10.1186/s12903019-0907-1

13. Misch C E , Perel M L , Wang H L , et al. Implant success, survival, and failure: the International Congress of Oral Implantologists (ICOI) Pisa Consensus Conference. Implant Dentistry, 2008, 17(1):5. https://doi.org/10.1097/id.0b013e3181676059

14. Pjetursson B E , Karoussis I, Walter Bürgin, et al. Patients' satisfaction following implant therapy. Clinical Oral Implants Research, 2005, 16(2):185-193. https://doi.org/10.1111/j.16000501.2004.01094.x 
15. Lane NE. Epidemiology, etiology, and diagnosis of osteoporosis. American journal of obstetrics and gynecology. 2006 Feb 1;194(2):S3-11. https://doi.org/10.1016/j.ajog.2005.08.047

16. Baldassarri $M$, Bonfante $E$, Suzuki $M$, et al. Mechanical properties of human bone surrounding plateau root form implants retrieved after 0.3-24 years of function. Journal of Biomedical Materials Research Part B: Applied Biomaterials, 2012, 100B(7):2015-2021. https://doi.org/10.1002/jbm.b.32786

17. Liu Xiangzhen, Shu Dalong, Guo Bing, Ran Wei. Comparison of the effect of osteotomy and abutment restoration in the treatment of insufficient occlusal space of dental implants [a] Oral and maxillofacial surgery special committee of Chinese Stomatological Association, oral and maxillofacial tumor special committee of Henan anti cancer association. The 12th National Oral and maxillofacial head and neck tumor internal medicine and vascular disease academic conference and the second oral and Maxillofacial Tumor Society Conference of Henan anti cancer association [C]. Oral and maxillofacial surgery special committee of Chinese Stomatological Association, oral and maxillofacial tumor special committee of Henan anti cancer association Committee: Chinese Stomatological Association, 2018:2

18. Markose J , Eshwar S , Srinivas S, et al. Clinical outcomes of ultrashort sloping shoulder implant design: A survival analysis. Clin Implant Dent Relat Res, 2018,20(4):646-652. https://doi.org/10.1111/cid.12608

19. Chou HY, Müftü S, Bozkaya D. Combined effects of implant insertion depth and alveolar bone quality on periimplant bone strain induced by a wide-diameter, short implant and a narrow-diameter, long implant. Journal of Prosthetic Dentistry, 2010, 104(5): 293-300. https://doi.org/10.1016/S00223913(10)60142-4

20. Lee E H, Ryu S M , Kim J Y, et al. Effects of Installation Depth on Survival of an HydroxyapatiteCoated Bicon Implant for Single-Tooth Restoration. Journal of Oral \& Maxillofacial Surgery, 2010, 68(6):1345-1352. https://doi.org/10.1016/j.joms.2009.12.010

21. De Siqueira R A, Fontão F N, Sartori I A, et al. Effect of different implant placement depths on crestal bone levels and soft tissue behavior: a randomized clinical trial. Clinical Oral Implants Research, 2017, 28: 1227-1233. https://doi.org/10.1111/clr.12946

22. Kappel S , Eiffler C , Lorenzo-Bermejo J , et al. Undetected residual cement on standard or individualized all-ceramic abutments with cemented zirconia single crowns - a prospective randomized pilot trial. Clinical Oral Implants Research, 2015. https://doi.org/10.1111/clr.12691

23. Seo C W, Seo J M. A technique for minimizing subgingival residual cement by using rubber dam for cement-retained implant crowns. Journal of Prosthetic Dentistry, 2017, 117(2): 327-328. https://doi.org/10.1016/j.prosdent.2016.08.024

24. Rayyan M M, Makarem H A. A modified technique for preventing excess cement around implant supported restoration margins. Journal of Prosthetic Dentistry, 2016, 116(6): 840-842. https://doi.org/10.1016/j.prosdent.2016.04.007 
25. Lee J H, Lee J B , Kim M Y , et al. Mechanical and biological complication rates of the modified lateral-screw-retained implant prosthesis in the posterior region: an alternative to the conventional Implant prosthetic system. Journal of Advanced Prosthodontics, 2016, 8(2):150-157 http://dx.doi.org/10.4047/jap.2016.8.2.150

26. Urdaneta R A , Chuang S K. The Survival of Short and Ultrashort Plateau Root Form Implants[M]// Short Implants. 2020.

27. Lombardo G, Signoriello A, Simancas-Pallares M, et al. Survival of Short and Ultra-Short LockingTaper Implants Supporting Single Crowns in the Posterior Mandible: A 3-Year Retrospective Study. J Oral Implantol. 2020, 46(4):396-406. https://doi.org/10.1563/aaid-joi-D-19-00190

28. Moreno-Hay I, Okeson JP. Does altering the occlusal vertical dimension produce temporomandibular disorders? A literature review. J Oral Rehabil. 2015;42:875-882. https://doi.org/10.1111/joor.12326

29. Schierz $O$, John M T , Schroeder E , et al. Association between anterior tooth wear and temporomandibular disorder pain in a German population. Journal of Prosthetic Dentistry, 2007, 97(5):305-309. https://doi.org/10.1016/j.prosdent.2007.03.006

30. Kanavakis G, Mehta N.The role of occlusal curvatures andmaxillary arch dimensions in patients with signs and symptoms of temporomandibular disorders.Angle Orthod, 2014, 84 (1) :96-102. https://doi.org/10.2319/111312-870.1

31. Yashiro K, Iwata A, Takada K, et al. Temporomandibular joint articulations on working side during chewing in adult females with cross-bite and mandibular asymmetry. Journal of Oral Rehabilitation, 2015, 42(3):163-172. https://doi.org/10.1111/joor.12266

\section{Figures}

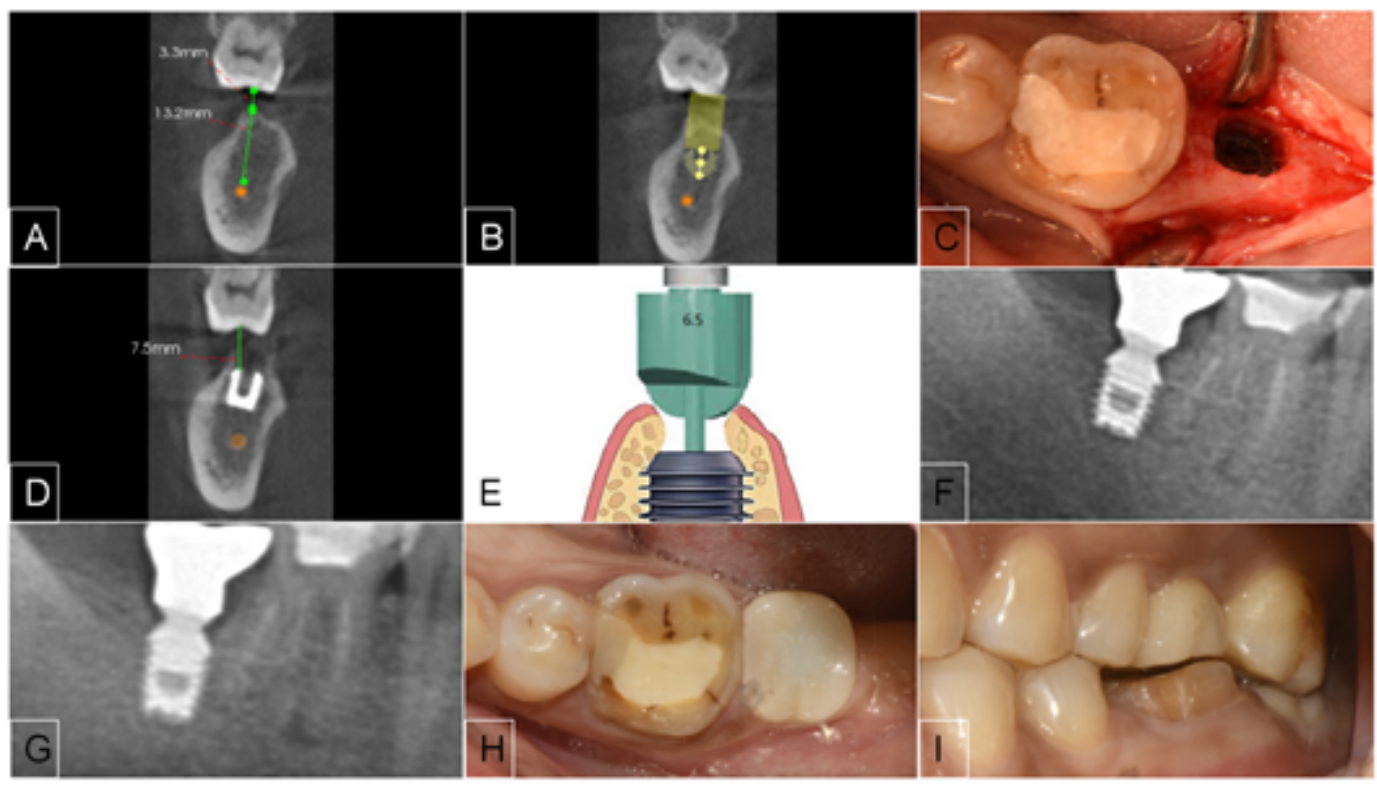

Figure 1 
Representative images of various clinical procedures: (A) preoperative CBCT analysis of patient's edentulous area that shows insufficient interocclusal space; (B) implant placement simulation; (C) deep implant placement (4 $\mathrm{mm}$ under the bone); (D) postoperative CBCT that shows the distance between implant neck and the opposite tooth was $>7 \mathrm{~mm}$; $(E)$ in the second-stage surgery, sulcus former was rotated on the guide pin to remove bone tissues that affected restoration; (F) all-ceramic crowns were used for implant restoration; $(\mathrm{G})$ image after 1 year; $(\mathrm{H})$ intraoral photo after 1 year; and $(\mathrm{I})$ intraoral photo after 1 year. 